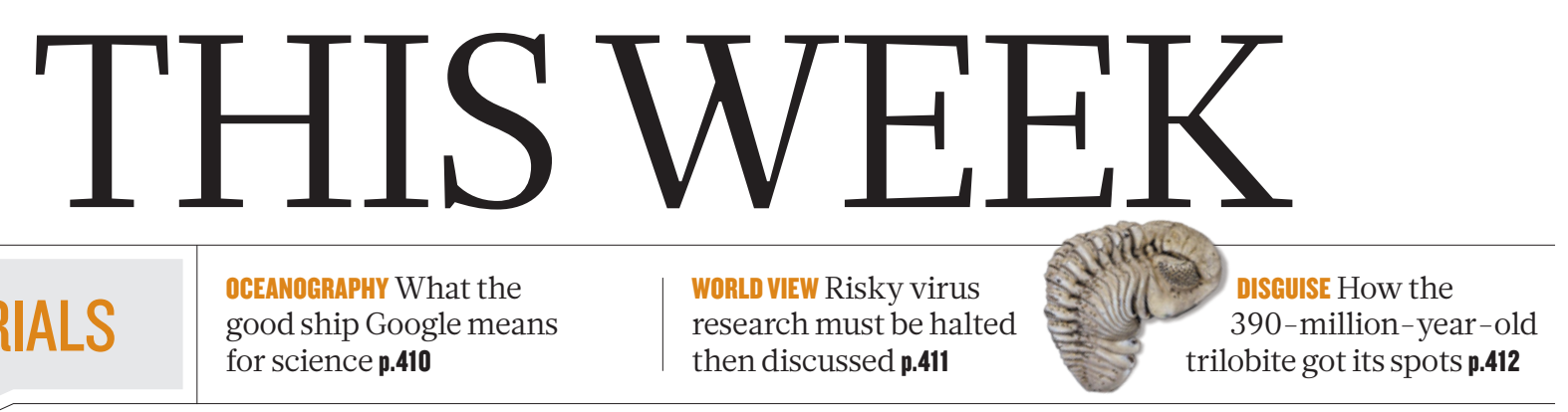

EDITORIALS for science $\mathbf{p . 4 1 0}$ research must be halte

then discussed $\mathbf{p . 4 1 1}$
Discuse How

trilobite got its spots p.412

\title{
Under the gun
}

\section{A ban on advocacy and promotion of gun control is keeping US agencies from conducting research that is sorely needed to inform policy on firearms and prevent shootings.}

$\mathrm{U}$ S president Barack Obama was expected this week to sign the bill that will fund the US government for the rest of the 2013 fiscal year. The bill contains the first congressional action on gun control since 20 children and six staff members were gunned down at Sandy Hook Elementary School in Newtown, Connecticut, on 14 December. But the congressional action is notable for the wrong reasons. Far from promising to shine badly needed light on the myriad unanswered questions around current policies on firearms, it instead continues restrictions on the gun-related research that is essential to wise policy-making. It is precisely the opposite of what is needed in the United States, where people murder each other with guns at about 20 times the rate in other wealthy nations.

We have been here before. After a gunman murdered 12 people and injured 58 in a Colorado cinema last July, this publication noted that the US National Rifle Association (NRA), through proxies in Congress, has since 1996 inserted restrictive language in the annual bill that funds the Centers for Disease Control and Prevention (CDC). The language prohibits the agency from spending any money "to advocate or promote gun control" (see Nature 488, 129; 2012).

In 2012, that language was extended to include all of the CDC's huge parent department, the Department of Health and Human Services, which includes the National Institutes of Health (NIH). The biomedical agency had drawn the gun lobby's ire by funding a study that concluded that guns did not protect their owners from being shot in an assault (C. C. Branas et al. Am. J. Public Health 99, 2034-2040; 2009). Admittedly, the study was criticized by some for methodological weaknesses. But NRA chief Wayne LaPierre used it to dismiss all NIH-funded, gun-relevant research as "public health junk science" in a 2010 online commentary. Soon, Congress extended the ban to encompass the NIH.

In the law that Obama signs this week, the NRA-backed prohibition will be continued. Strictly read, it does nothing to bar research, which is distinct from advocacy and promotion, Obama said in January, as he announced his response to the Newtown killings.

That response included, commendably, a memorandum that directed the $\mathrm{CDC}$ and other agencies to launch a vigorous effort to study the causes of gun violence and ways to prevent it. Obama asked Congress to provide US $\$ 10$ million in new money to the CDC to support its investigation of the most pressing questions, adding that White House lawyers do not interpret such research as contravening the existing prohibition. His administration argued in an accompanying document: "Research on gun violence is not advocacy; it is critical public health research that gives all Americans information they need."

And they do need it. The 17-year dearth of government-funded research, and a parallel chill on collection of gun-related data by US agencies, have left politicians without the most rudimentary information needed to inform policy-making. Consider, for instance, that the most recent Department of Justice data on the proportion of gun sales occurring between private individuals - as opposed to sales by

licensed dealers - date to 1994. Not since 2004 has the CDC included firearms-related questions in its Behavioral Risk Factor Surveillance System questionnaire, an instrument used to shape state policies. The number of academic publications relevant to firearm violence has fallen by $60 \%$ since peaking in 1996 , according to an analysis by the coalition Mayors Against Illegal Guns, which looked at trends from 1960 to 2010.

"Obama's research agenda will not get far in the presence of the existing prohibition."

But however strong the need, Obama's research agenda will not get far in the presence of the existing prohibition, which was crafted to intimidate researchers and funding agencies - and has been having precisely that effect.

The irony is that the gun lobby and its congressional allies might benefit from rigorous research. Would a robust study reveal that state laws allowing citizens to carry concealed weapons have resulted in more or fewer deaths? We don't know. Would the spiking homicide rate in Chicago, Illinois, be higher still if it were not for the city's restrictive gun laws, or are those laws ineffective? We don't know. Does a limit on assault weapons reduce the overall rate of firearms injuries and deaths? We don't know.

How many Newtowns will it take until Congress funds the research that will answer these and other pressing questions? Only strong evidence-based policies would allow politicians to tell grieving parents after the next slaying: we are doing everything we can to stop this happening again.

\section{Disciplinary action} How scientists share and reuse information is driven by technology but shaped by discipline.

\section{$\mathrm{T}$} The words 'technology' and 'revolution' are being bandied around a lot in scientific publishing - and this week Nature presents a special series of articles that explores the industry's changing landscape (see page 425). But beyond the early adopters of digital technologies who shout freedom from the rooftops and the publishers who look on nervously, what do researchers make of it? Would it surprise you to learn, for example, that more than one-third of academic chemists disagree with the statement "all papers should be published open access"?

The transformation of research publishing is less a revolution and more a war of attrition. Battle lines were drawn long ago and all sides are well dug-in. In 2001, this journal published a series of viewpoints on the future of 'e-access to the primary literature' (see go.nature.com/pezj84). 